\title{
FILOSOFÍA DE LA ABDUCCIÓN: PEIRCE Y POE
}

En la historia de la filosofía Charles Sanders Peirce (Cambridge, Massachusetts, 1839-1914) parece ser el más original, profundo y versátil de los fundadores del pragmatismo. También el más difícil. Su pensamiento es laberíntico y uno se pierde entre ambigüedades y contradicciones. Su prosa es intrincada y uno se queda a oscuras entre tecnicismos y neologismos. Con todo, es genial, y algunas de sus ocurrencias lo exaltan a uno como si fueran invitaciones al vuelo. Nunca concibió un libro pero sus artículos y apuntes, reunidos póstumamente en ocho volúmenes (Collected Papers, 1931-1958), han influido, y siguen influyendo, en especialistas de epistemología, logística, semiótica, positivismo lógico, gramática generativa y metodología de las ciencias experimentales.

Lo que más me interesa de su filosofía, no porque me convenza, sino porque me hace pensar en los cuentos detectivescos de Edgar Allan Poe, es el término "abducción", acuñado por Peirce para designar un proceso discursivo diferente de los de la "deducción" y la "inducción".

Nadie puede haberse olvidado de las definiciones que nos enseñaron en el colegio secundario: el razonamiento deductivo va de lo universal a lo particular y, al revés, el razonamiento inductivo va de lo particular a lo universal. Si Peirce hubiera sido nuestro profesor en el colegio secundario no nos habría enseñado eso. No es verdad, decía, que la deducción baja de lo general a lo particular y que la inducción sube de lo particular a lo general porque la premisa mayor de la deducción se basa en observaciones de hechos particulares y la premisa mayor de la inducción no puede menos de partir de previas nociones generales. Según él, ninguno de los dos razonamientos aporta nuevas ideas a la ciencia. ¿Por qué no? Porque en la deducción, aunque nos parezca 
que una vez que aceptamos un principio general hay que deseen. der necesariamente, mediante un nexo lógico, a una conclusiór singular, lo cierto es que la conclusión no hace más que analiza: lo que ya estaba en la premisa, sin ampliarlo. Y en la inducciór nos parece ascender de los objetos singulares que observamos : un principio general, pero este principio vale solamente para li misma clase de objetos; es decir, que con la inducción estamo clasificando, no inventando. Más innovador sería un razona miento premonitorio que, apoyándose en una observación, se in clinara hacia una generalización y en el camino de la observacló a la generalización seleccionara y adoptara una hipótesis qu habría que verificar o refutar con nuevas observaciones. A est vertiginoso proceso Peirce lo bautiza con el nombre de "abduc ción". Los descubrimientos científicos no se deben ni a la deduc ción ni a la inducción sino a la abducción.

¿Qué es la abducción, al final de cuentas? "Es un modo d aventurar hipótesis en la fase inicial del razonamiento". Peirc propone el siguiente modelo de razonamientos:

\section{DEDUCCIÓN}

Premisa mayor: Todos los porotos de esta bolsa son blancos

Premisa menor: Estos porotos son de esta bolsa

Conclusión: Estos porotos son blancos

\section{INDUCGIÓN}

Premisa menor: Estos porotos son de esta bolsa

Conclusión: Estos porotos son blancos

Premisa mayor: Todos los porotos de esta bolsa son blancos

\section{ABDUCGIÓN}

Premisa mayor: Todos los porotos de esta bolsa son blancos

Conclusión: Estos porotos son blancos

Premisa menor: Estos porotos son de esta bolsa

Antes de describir el complejo proceso mental de la abdu ción conviene despejar una posible duda. Este ejemplo de indu ción desconcierta porque concluir con que "todos los porotos $c$ esta bolsa son blancos" no es lógico. Lo prudente sería deci "Todos o solamente algunos porotos de esta bolsa son blancos' Es que, para Peirce, la conclusión, en el razonamiento inductivı puede ser falsa aunque las premisas sean veraderas. En otras p: labras, lo que la conclusión se arriesga a afirmar es algo que exc de lo dicho en las premisas. Para verificar que "todos los porotı 
de esta bolsa son blancos" se necesitarían métodos extralógicos. Con ese desconcertante ejemplo de inducción Peirce prepara la defensa de su teoría de la abducción como razonamiento extralógico. La abducción es una hopótesis, una corazonada, una conjetura, un pálpito, una intuición, no mística sino instintiva, según se verá más adelante. O sea, que la abducción es la forma más innovadora del conocimiento. Para Peirce la deducción se contiene a sí misma, pues la conclusión se encuentra contenida en las premisas. En cambio la inducción y la abducción no se contienen a sí mismas por la sencilla razón de que necesitan ser verificadas mediante la observación de hechos.

La inducción también propone hipótesis, y por eso se la suele confundir con la abducción, pero en los actos de la mente la inducción se pone a trabajar después que la abducción rumbeó hacia una verdad probable. La inducción se beneficia, pues, de las previas conjeturas de la abducción. Ambas maneras de pensar se asemejan y cuesta distinguirlas. Un distingo sería éste: las inferencias de la inducción son firmes, se basan en hechos percibidos y como terminan por aplicarse a la misma clase de hechos no corren grandes riesgos de equivocarse; en cambio las inferencias de la abducción empiezan a formarse en un estado emocional, imaginativo, creador, y sus hipótesis sí corren grandes riesgos de equivocarse. Lo cual no menoscaba su valor pues la abducción puede, de un salto feliz, adelantarse en el progreso de las ciencias.

Con el razonamiento abductivo respondemos a una realidad que nos choca. Queremos entenderla. La entenderemos, naturalmente, con las formas innatas del entendimiento. Pongamos el caso de una persona que se sorprende ante fenómenos inesperados (hechos, objetos o circunstancias). Presiente que está a punto de averiguar por qué le causaron sorpresa. Advierte, entre los componentes de esos fenómenos, una curiosa relación. Es más: reconoce que esa relación es característica de ciertos conceptos que tenía ya formados en su mente. Entonces, con la mente así educada por experiencias del pasado, se le ocurre una hipótesis que aclara lo que hubo de sorprendente en los fenómenos que le llamaron la atención... A veces la hipótesis es una falsa corazonada; a veces la comprobamos con los métodos de las ciencias empíricas, en cuyo caso nos ayuda en el deseo de resolver un problema. Complicado, ¿no? A ver si lo simplifico volviendo a los porotos. Observo un hecho que me llama la atención ("estos porotos son blancos") e inmediatamente comienza el proceso abductivo que tiende a comprender la singularidad de ese hecho. 
Se me presenta en la mente, como en un relámpago, un principic general, una ley natural, una experiencia cualquiera a la que po demos llamar premisa mayor ("todos los porotos de esta bolsi son blancos"') y de aquí paso a lo que podemos llamar premisi menor pero es el resultado del proceso abductivo ("estos poroto son de esta bolsa'). El proceso de la abducción se desenvuelv، entre la conclusión (que es la observación del hecho) y la premis: mayor, y concluye con una hipótesis a la que hay que constatar

En suma, que la abducción es el primer paso en cualquie pesquisa. El segundo es la deducción, que saca las consecuencia necesarias de la hipótesis adoptada. El tercer paso es la induc ción, que compara las predicciones de la hipótesis con los resulta dos de cuidadosos experimentos. La abducción nos proporcion informaciones nuevas. No así la deducción y la inducción, qu sirven para corroborar la abducción.

Ahora bien, muchas de las hipótesis que nuestra mente cons truye son erróneas pero en mayor número son verdaderas. Est plantea un serio problema antropológico. Si el Homo Sapiens el giera las hipótesis al azar no habría razón para que acertase má veces de las que desacierta. Tiene que haber, pues, en el nac miento de las hipótesis, algo más que un juego de dados. Tien que haber siquiera un pálpito. "La abducción es, después de tc do, una corazonada y nada más", admite Peirce, nada menc que el padre de la criatura, y luego se apresura a advertirnos qui aunque nos ilumina repentinamente, como un relámpago, no t una "intuición", si por intuición entendemos un conocimient infalible, determinado místicamente desde fuera de la concieı cia. Por el contrario, la abducción es una sospecha muy falib que surge de la conciencia y está determinada por la naturalezi Como que es un instinto natural. "La mente humana", afirm Peirce, "habiéndose desarrollado bajo la influencia de las ley' de la naturaleza, piensa de acuerdo con estructuras naturales' "Es evidente que si el hombre no hubiese tenido una luz conn tural, una luz interior que le sugiriera suposiciones que con fr cuencia resultaron correctas, nuestra especie ya se habría exti? guido por ser inepta para las luchas por la existencia". "Toc el conocimiento humano, incluyendo los vuelos más altos de ciencia, es el desenvolvimiento de nuestros instintos animales: La mente del razonador, formada por selección natural a lo lar: de la evolución biológica, es afín a los modos de operar de la $n$ turaleza y por tanto está predispuesta a barruntar verdades tales. 
Una de las muchas paradojas en la filosofía de Peirce es la de fundar su lógica en datos biológicos, antropológicos y psicológicos. ¿Cómo atribuir a la abducción una forma lógica si su origen es instintivo? Ah, es que Peirce alega que las conjeturas presuponen juicios e inferencias, o sea, un control racional.

De los muchos ejemplos de abducción que Peirce nos dio eligiré uno que fue vivido dramáticamente. Es una anécdota detectivesca. Él mismo la contó, larga y minuciosamente. En un viaje por barco le robaron el reloj. Se las arregló para conversar con los camareros. Cuando ya desesperaba por no vislumbrar un solo signo que denunciara al culpable, "una voz interior", sin darle razones, le sopló: “ese negro que está ahí es el ladrón", y tras accidentadas pesquisas resultó que su presentimiento había sido verdadero. Peirce, que se complacía en demostrar sus condiciones de pesquisante, contó esta anécdota como ilustración de su teoría sobre la tendencia humana a sospechar y sobre el hecho de que acertamos con frecuencia aun en sospechas infundadas.

Dije al comienzo que el concepto de "abducción" me hace pensar en algunos cuentos de Poe: en "El gato negro", "Un descenso al Maelstrom", "El escarabajo de oro", "La carta robada", "Tú eres el hombre" y sobre todo en "Los crímenes de la calle Morgue", que en 1841 fundó el género detectivesco, tal como se lo sigue cultivando hoy. En este cuento el protagonista $\mathrm{Au}-$ guste Dupin describe su método y después lo usa para resolver un problema policial.

En la primera escena el narrador cuenta su amistad con Dupin. Una noche pasean por las calles de París sin pronunciar ni una sola palabra. De repente Dupin rompe el silencio para decir: "De veras, es demasiado pequeño". El meditabundo narrador contesta: "Sin duda" y se detiene asombrado. ¿Cómo ha podido adivinar Dupin que, en ese preciso instante, él estaba pensando en que cierto actor era demasiado pequeño para representar papeles trágicos?

La detallada explicación que Dupin da al narrador es ya famosa entre los críticos literarios. Un vendedor de frutas había atropellado al narrador. A partir de ese instante, y durante una marcha de quince minutos, Dupin, basándose en conversaciones ánteriores y en la observación de los gestos del narrador - la dirección de sus miradas, el movimiento de los labios, la ironía de una sonrisa, los cambios en la postura del cuerpo- se instaló mentalmente en su monólogo interior. Cuando el narrador, en el curso de su asociación de ideas, recordó al actor bajito, Dupin 
pudo interrumpirlo con una frase que coincidió exactamente co ese recuerdo.

No mucho después Dupin da otra prueba de sus extraordina rias dotes para proponer hipótesis que acaban por ser confirme das por los hechos. Una mujer y su hija aparecen asesinadas d un modo atroz en un local cerrado. La policía está despistad ć ¿cómo logró escapar el brutal asesino? Dupin achaca ese fracas de la policía a que no es metódica, no ve el bosque por mirar lc árboles y sus pesquisas no se ciñen a la realidad. En cambio ، con sus observaciones y presunciones descubre que el criminal $\mathrm{n}$ pudo haber sido humano. En efecto, fue un orangután.

Peirce había sido un lector atento de Poe. Lo cita varias vi ees, analizó en uno de sus escritos los versos de "El cuervo y al referirse a "Los crímenes de la calle Morgue" parece habé aludido a la semejanza entre la "ratiocionation" de Poe y s propia "abduction" (Collected Papers, volumen VI, libro II, cap tulo 3 subtitulado "Musement"). El tema de este capítulo , una indagación sobre la existencia de Dios pero lo cierto es qu allí no se cita a un teólogo sino a un detective: al caballero $A_{1}$ guste Dupin, de Poe. Con los intraducibles términos "mus ment" y "Play of Musement" Peirce describe su fluir psíquic cuando está por formular una hipótesis. Su descripción coincic con la que Poe hace de las cavilaciones de Dupin. Aun los det lles son iguales: una agradable disposición del ánimo ocioso di rante un paseo nocturno de pocos minutos, abandonándose la imaginación en una especie de juego sin reglas, sin propósit prácticos, con absoluta libertad, hasta que de súbito se le prese: ta la hipótesis adecuada para despejar un enigma. Si en el cuen de Poe el narrador caracteriza la doble personalidad de Dup como "creadora y analítica", Peirce, al caracterizar la medit ción como una serie de abducciones, recomienda que uno co verse consigo mismo, "un yo con el otro yo". Poe había hecl decir a Dupin: "Me parece que este misterio es considerado i soluble por la misma razón que debería considerarse de fácil s lución... Es por los desvíos del plano de lo ordinario que razón halla su camino, si esto es posible, en busca de la verdad Peirce recuerda esta frase y, a juzgar por el contexto, la interpr ta así: la meditación espontánea, inspiradora, libre, gratuit lúdica de Dupin favoreció el proceso de la abducción y de hipótesis correcta. Gracias a esa imaginación creadora, un c men que por ser truculento pareció insoluble a la policía fue fácil solución para Dupin. 
No es que Poe haya influido en Peirce sino que Peirce proyecta sobre el método detectivesco de Poe su personal teoría de la abducción. Habrá lectores de hoy que se sientan tentados a opinar que el cuento de detectives, desde Poe y Conan Doyle hasta Dorothy Sayers y Raymond Chandler, es la forma literaria que mejor corresponde a la teoría de la abducción. Por mi parte, lo que veo de común entre Poe y Peirce (además de la mayúscula P) es que ambos se mueven en un círculo vicioso: el personaje Dupin acierta porque el autor Poe quiso que acertase, y la teoría de Peirce sobre el carácter instintivo de las hipótesis es, ella misma, una hipótesis.

EnRIQUe ANDERson Imbert

Harvard University 
